\title{
Agro-Climatic Conditions and Regional Technical Inefficiencies in Agriculture
}

\author{
Nazmi Demir and Syed F. Mahmud \\ Assistant and visiting associate professors, Bilkent University, \\ 06533 Bilkent, Ankara ,Turkey \\ (phone: 90-312-2901640; fax: 90-312-2904383; \\ e-mails:nazmi@bilkent.edu.tr; syed@bilkent.edu.tr).
}

Received January 2002, accepted August 2002

\begin{abstract}
A survey of applications of the Technical Inefficiency Effects (TIE) model suggests that agro-climatic and other environment variables are customarily omitted in the model specifications. The justification for such an omission is the assumption that these variables are beyond the control of the farmers and therefore should be treated as random variables. In this paper, we argue that in applications dealing with regional agricultural data, agro-climatic variables should not be treated as pure random terms. Historical differences in agro-climatic conditions are known with a reasonable degree of certainty across a larger region. Therefore, omission of such variables from the analysis may lead to inaccurate interregional technical inefficiency comparisons. In order to demonstrate the importance of agro-climatic variables in such analyses, we estimate the TIE model for Turkey. A translog stochastic frontier production function with agro-climatic variables such as rainfall and land quality is estimated, and it is shown not only that the agro-climatic variables are statistically significant but also that their omission substantially affects mean output elasticities and relative technical efficiencies.
\end{abstract}

Une étude sur les applications du modèle de l'effet d'inefficacité technique (EIT) laisse à supposer que les variables agro-climatiques et les autres variables environnementales sont comme d'habitude omises dans les spécifications du modèle. Une telle omission est justifiée par l'hypothèse selon laquelle ces variables sont en dehors du contrôle des fermiers et devraient être considérées comme des variables aléatoires. Dans ce communiqué, nous affirmons que dans les applications concernant les données agricoles régionales, ces variables agro-climatiques ne doivent pas être traitées comme de simples termes aléatoires. Les différences historiques dans les conditions agro-climatiques sont connues avec un degré raisonnable de certitudes pour une grande région. Aussi l'omission de telles variables dans l'analyse peut-elle donner lieu à de fausses comparaisons interrégionales d'inefficacité technique. Afin de démontrer l'importance des variables agro-climatiques dans de telles analyses, nous considérons le modèle de l'effet d'inefficacité techniques de la Turquie. Il s'agit d'une fonction de production frontalière translogue et stochastique avec des variables agro-climatiques telles que la pluviosité, la qualité de sol et d'autres variables. Nous démontrons que les variables agro-climatiques sont non seulement importantes statistiquement, mais que leur omission influence essentiellement les élasticités moyennes de production ainsi que les efficacités techniques relatives.

\section{INTRODUCTION}

The standard parametric approach to the measurement of technical efficiency (TE) in agriculture entails an estimation of a stochastic frontier production function, with a composite error term (Aigner, Lovell and Schmidt 1977; Meeusen and van den Broeck 1977). ${ }^{1}$ The composite 
term involves an unobservable random variable related to the technical inefficiency of the farms and a random error in a typical regression model. The latter is assumed to capture random variations in agricultural output due to measurement errors and variations in other factors that are beyond the control of the farmers. Various distributional forms have been employed for the error term associated to technical inefficiency. ${ }^{2}$ For example agro-climatic conditions such as land quality and rainfall could be considered as one of the sources of such random variations.

Agro-climatic and other environmental variables are normally ignored in the empirical specification of agricultural stochastic production function models, on the assumption that they are beyond the control of the farmers. In this paper, we argue that the differences in agro-climatic conditions are historically known across various agricultural zones and therefore should not be treated as random. ${ }^{3}$ The exclusion of these variables may incorrectly attribute the impact, on TE levels, of agro-climatic conditions to the farms and/or agro-regions. Moreover, the uncontrollable agro-climatic factors interact with land, labor and capital inputs and so the use of inputs is likely to depend on factors such as rainfall. If we decide to include agro-climatic conditions, the concept of model specification also becomes an important issue. Different specifications of the technical inefficiency effect (TIE) are proposed in literature (for example, Battese and Coelli 1995; Battese and Broca 1997). In this paper, we attempt to account for the effects of agro-climatic variables on TE with different model specifications using aggregate provincial data. We expect more meaningful estimates of TE measures for the provinces by disentangling the possible effects of the location-specific environmental variables. A translog stochastic TIE model is applied to represent data from 67 provinces of Turkish agriculture for the period 1993-95. Model interactions of uncontrollable factors with level of input usage are also incorporated through a nonneutral specification of the TIE. We think that interregional comparisons of TE measures in agricultural production may become more useful for agricultural policy decision making when the uncontrollable environmental effects are incorporated in the analysis.

Review of the studies of agricultural production frontiers employing provincial or regional data suggests that these models primarily focus on farm-specific characteristics while estimating technical efficiencies and show no concern to the broader environmental factors, such as soil quality and climatic conditions. ${ }^{4}$ Ali and Chaudhry (1990) employed Punjab data in Pakistan, Brada and King (1994) analyzed data on different agricultural regions of Poland, Kalirajan, Obwona and Zhao (1996) worked with data from Chinese provincial-level agriculture, and Battese, Malik and Gill (1996) analyzed data on four districts of Pakistan. All these studies, which employed provincial and/or regional data, ignored environmental variables in their analysis. ${ }^{5}$

\section{THE MODEL}

We follow Huang and Liu's (1994) work on the Taiwanese electronic industry. Huang and Liu introduced the assumption of nonneutral effects in their model in which interaction terms between firm-specific factors and production inputs were incorporated. Battese and Broca (1997) also used these interactions to further explain technical inefficiency. This nonneutral model is useful in agricultural applications where one would expect that farm-specific variables such as the education of the farmer would have a different effect on technical inefficiency at different levels of inputs. In this paper, we incorporate this framework using aggre- 
gate provincial level agricultural data as opposed to farm level data. We also assume that agro-climatic variables may affect the productivity and therefore we include these variables in the production function as well as in the inefficiency model.

The model specification is:

$$
\ln V A_{i t}=\beta_{0}+\sum_{j} \beta_{j} \ln X_{j i t}+\sum_{j} \sum_{m} \beta_{j m} \ln X_{j i t} \ln X_{m i t}+V_{i t}-U_{i t}
$$

where:

subscripts $i$ and $t=$ the $i$ th province $(i=1,2, \ldots, 67)$ and the $t$ th year of observation

$j, m=A, L, K, Q, R$

$V A_{i t}=$ the agricultural value-added in province $i$

$X$ variables = land, $A$, labor, $L$, capital, $K$, land quality, $Q$, and precipitation, $R$.

The $V_{i t}$ 's are assumed to be independent and identically distributed as normal random variables with zero mean and constant variance $\sigma_{v}{ }^{2}$, and are also assumed to be independent of the $U_{i t}$. The $U_{i t}$ 's are assumed to be nonnegative and independently distributed random terms, which are obtained by truncation (at zero) of a normal distribution with variance $\sigma^{2}$ and mean $\mu_{i t}$, where $\mu_{i t}$ is defined as:

$$
\mu_{i t}=\delta_{0}+\sum_{j}^{4} \delta_{j} Z_{j i t}+\sum_{j}^{4} \sum_{k}^{3} \delta_{j k} Z_{j i t} \ln X_{k i t}
$$

The $Z$ variables include, land ownership distribution (measured by Gini coefficient $G$ ), land quality (measured by a land quality index $Q$ ), general cropping pattern (a dummy variable taking 1 for intensive cultivation, 0 for cereals and traditional livestock $C$ ) and rainfall (a dummy variable taking 1 for precipitation above the national average $R$ ), and $\delta$ 's are the parameters to be estimated. Maximum likelihood estimates of all the parameters of Eqs. 1 and 2 were obtained simultaneously using the program FRONTIER 4.1 (Coelli 1996). The specific forms of these likelihood functions, which are to be maximized, are reported in Battese and Coelli (1993) and Huang and Liu (1994).

\section{DATA AND DISCUSSION OF RESULTS}

Data from 67 provinces, aggregated at provincial level, covering the years 1993, 1994 and 1995 have been employed in this paper. A summary of variables is provided in Table 1.

The value-added from agriculture (crop and animal husbandry) averaged TL206 billion (TL is the Turkish currency unit) in 1987 prices. The standard deviations show there is considerable variation among provinces. The size of the standard deviations indicates large interprovincial differences in agricultural land, labor and capital. Capital is a linear combination, based on the principal-component approach, of various agricultural capital stocks including agricultural machinery. ${ }^{6}$ The dummy for general crop pattern is 1 if a province derives more than $50 \%$ of its agricultural output, in value, from intensive cultivation (generally industrial crops, fruits and vegetables). Land quality is the percentage of areas in top quality 4 classes in all agricultural land (8 classes). Land quality in each class is a combination of topography, soil fertility, soil texture and other factors (KHGM). Land ownership distribution is measured by Gini coefficients estimated for provinces from the Agricultural Census data for the year 1991 (DIE 1994) and assumed to be constant for the period 1993-95. 


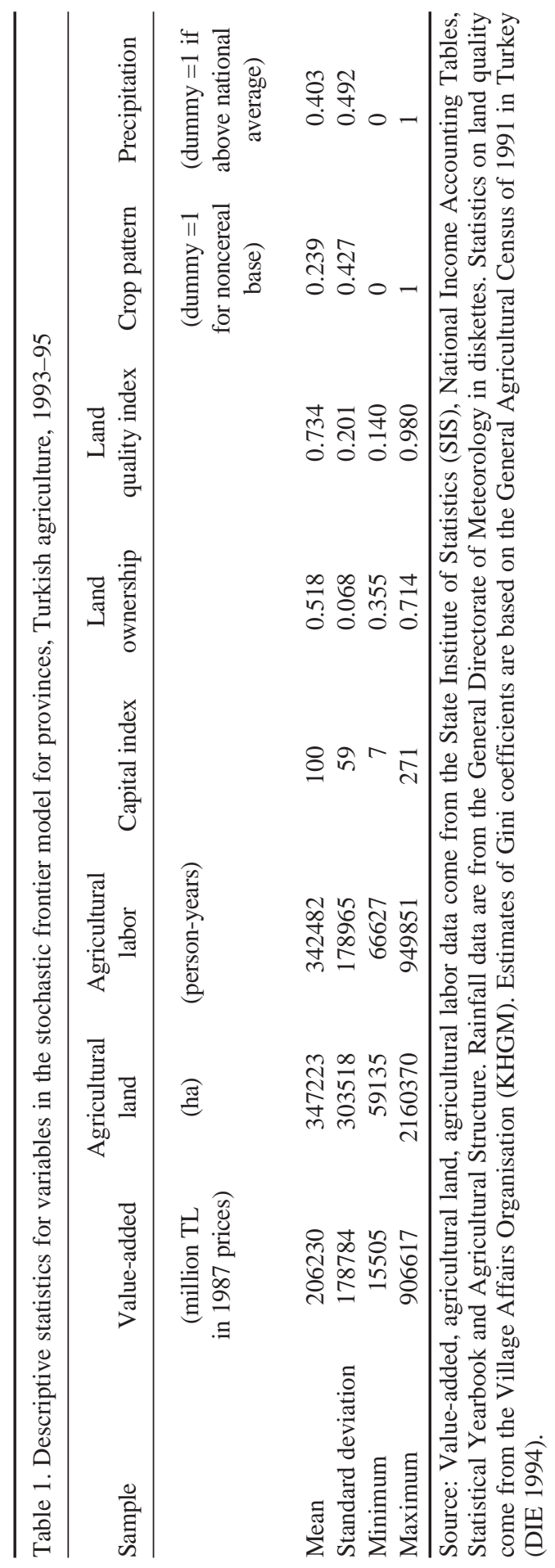


Table 2. Tests of null hypotheses based on the likelihood ratio statistic a for parameters of the stochastic frontier production function for provinces in Turkish agriculture

\begin{tabular}{llclll}
\hline Null hypotheses & $\begin{array}{l}\text { Meaning of the } \\
\text { null hypotheses }\end{array}$ & $\begin{array}{c}\text { Log-likelihood } \\
\text { function }\end{array}$ & $\begin{array}{c}\text { Critical } \\
\text { values at 5\% }\end{array}$ & Decision \\
\hline
\end{tabular}

Model 4

Given the nonneutral

translog model

Model 1

$H_{0:} \delta_{G}=\delta_{Q}=\delta_{C}=\delta_{R}=0$

There are no linear and

$-87$.

50

interaction terms for TIEs,

50.6 $38.89 \quad$ Reject $H_{0}$

and Model 2 restrictions

and $R$ and $Q$ have no effect

on productivity and

efficiency

Model 2

$H_{0:} \delta_{i j}=0$ and

Model 3 restrictions

$\begin{array}{lllll}\text { Neutral model is adequate } & -61.8 & 40.2 & 33.92 & \text { Reject } H_{0}\end{array}$ and $R$ and $Q$ have no effect on productivity and efficiency

Model 3

$H_{0}: \beta_{Q}=\beta_{R}=\beta_{Q Q}=\beta_{A Q}$

$R$ and $Q$ have no effect on $\quad-41.7$

22.0

18.31

Reject $H_{0}$

$=\beta_{A R}=\beta_{L Q}=\beta_{L R}=\beta_{K Q}$

productivity

$=\beta_{K R}=\beta_{Q R}=0$

aThe likelihood ratio is $\gamma=-2 \mathrm{Ln}\left(H_{0} / H_{1}\right)$ where $H_{0}$ and $H_{1}$ are the likelihood functions under the null and alternative hypotheses respectively.

d.f. $=$ Number of restricted parameters.

The maximum likelihood estimates of the parameters of the translog stochastic frontier production function in Eqs. 1 and 2 together with those of three submodels with various restrictions are given in Table A-1 of the Appendix. One would generally expect heteroscedastic error structure while using provincial data. With the Goldfeld-Quandt test, we did not find any evidence for the presence of the heteroscedasticity. Model 1 does not include any agro-climatic variables. Model 2 includes agro-climatic variables only in the inefficiency function with neutral effects. Model 3 is a nonneutral specification with agro-climatic variables in the TIE function. Three separate null hypotheses were tested using the likelihood ratio test and the results are presented in Table 2.

All the null hypotheses in question were strongly rejected by the data. And therefore no submodel that is considered is an adequate representation for the data, given the specification of the stochastic frontier model in Eqs. 1 and 2 (see Table 2). ${ }^{7}$ Given Model 4, the null hypothesis that all coefficients associated with the agro-climatic variables are zero (Model 1) is strongly rejected and therefore Model 1 does not adequately represent the data. The second null hypothesis that the neutral specification together with restrictions that rainfall and land quality have no effect on productivity and efficiency, given Model 4, is also rejected. Finally, the rejection of the third null 
hypothesis, that the two agro-climatic variables rainfall and land quality have no effect on productivity, implies that even Model 3, with three traditional production inputs together with the environmental variables, does not adequately represent the data. We were particularly interested in the significance of the agro-climatic variables and most of them in both neutral and nonneutral models were found to be significant. All the coefficients carry the correct signs (negative) as expected. In the neutral specification (Model 2) except for the Gini coefficient, all other coefficients are significantly different from zero. For the nonneutral model (Model 4), the marginal contribution of environmental variables to the technical efficiency has been computed as indicated in Battese and Broca (1997). The terms $\partial E\left(e^{-u}\right) / \partial Z_{k}$ are functions of variable inputs, $X$ 's, and therefore these marginal contributions have been evaluated at sample means. The marginal contributions to technical efficiency are estimated to be 0.658 for Gini, 0.073 for land quality, 0.102 for general crop pattern and 0.166 for rainfall. These results indicate that technical efficiency is positively related to the environmental variables.

Elasticities of mean output with respect to land, labor and capital for the Model 1 and Model 2 are read directly from columns 2 and 3 of Table A-1 in the Appendix. The input variables employed are mean corrected and therefore the first-order parameters of Model 1 and Model 2 are output elasticities evaluated at sample means. They all are significant, except for the coefficient of land in the neutral model. For the Model 3 and Model 4, the elasticity of mean output $\left[\partial \operatorname{Ln} E\left(V A_{i}\right) / \partial \operatorname{Ln} X_{k}\right]$ equals the elasticity of the frontier output (or the elasticity of best practice production) with respect to input $k$ minus the elasticity of technical efficiency with respect to input $k\left[C_{i}\left(\partial \mu_{i} / \partial \operatorname{Ln} X_{k}\right)\right]$ where the value of $C_{i}$ is determined by the density and distribution functions, given $\mu_{i}$ and $\sigma$ of the standard normal random variable (Huang and Liu 1994; Battese and Broca 1997). The elasticities and returns to scale estimated at the mean levels of inputs and of environmental variables are presented in Table 3.

The elasticities of mean output with respect to inputs are positive in all models except for the elasticity of output with respect to labor in Model 3. ${ }^{8}$ In Model 4, a $1 \%$ increase in land, labor and capital contributes $0.67,0.35$ and $0.11 \%$, respectively, to the mean output. The largest contribution to the mean output comes from land.

\section{TECHNICAL EFFICIENCIES}

The descriptive statistics of the technical efficiency (TE) from the translog stochastic frontier for the four models are reported in Table 4. The inclusion of the environmental variables and specification of the models do appear to affect mean technical efficiency. The result suggests that the average performance, in terms of technical efficiencies, of the provinces based on Model 4 is $62 \%$ compared with that of the best practice provinces. The standard deviation of the mean efficiency from Model 4 is found to be considerably larger than the other models. A similar result was obtained by Huang and Liu $(1994,177)$. One explanation of this result could be that in the nonneutral specification, the marginal contribution of production inputs also depends on the agro-climatic conditions in each province. Thus, provinces with different levels of factor input utilization are expected to gain (or lose), in terms of TEs, directly or through interactions with favorable (or limiting) agro-climatic conditions with the result of a wider range of TEs than those of the neutral one.

These differences in mean technical efficiencies and standard deviations are also highlighted from the frequency distributions of TE scores in Figures, 1a, 1b, 1c and 1d. The rank- 
Table 3. Elasticities of mean output and returns to scale with and without environmental variables inputs

\begin{tabular}{lcccc}
\hline & & \multicolumn{3}{c}{ With environmental variables } \\
\cline { 3 - 5 } & $\begin{array}{c}\text { Without } \\
\text { environmental variables } \\
\text { Model 1 }\end{array}$ & $\begin{array}{c}\text { Neutral } \\
\text { Model 2 }\end{array}$ & $\begin{array}{c}\text { Nonneutral } \\
\text { Model 3 }\end{array}$ & $\begin{array}{c}\text { Nonneutral } \\
\text { Model 4 }\end{array}$ \\
\hline Land & 0.208 & 0.321 & 0.561 & 0.671 \\
Labor & 0.533 & 0.197 & -0.101 & 0.348 \\
Capital & 0.712 & 0.663 & 0.600 & 0.105 \\
Returns to scale & 1.453 & 1.181 & 1.061 & 1.124 \\
\hline
\end{tabular}

Table 4. Descriptive statistics of TEs from four models for 67 provinces of Turkish agriculture

\begin{tabular}{lcccc} 
& \multirow{2}{*}{$\begin{array}{c}\text { Without } \\
\text { Sample }\end{array}$} & \multicolumn{3}{c}{ With environmental variables } \\
\cline { 3 - 5 } & Model 1 & Neutral & Nonneutral & Nonneutral \\
Model 2 & Model 4 \\
\hline Mean & 0.52 & 0.46 & 0.42 & 0.62 \\
Standard deviation & 0.20 & 0.17 & 0.24 & 0.26 \\
Maximum & 1.00 & 0.96 & 1.00 & 0.97 \\
Minimum & 0.18 & 0.17 & 0.02 & 0.12 \\
\hline
\end{tabular}

ing of provinces, in terms of their technical efficiency scores, changes considerably for different model specifications and different regions.

As expected, when the agro-climatic conditions are taken into account, provinces at locations with relatively unfavorable environmental conditions, such as the middle and eastern regions, are able to gain in terms of technical efficiency and vice versa. For example, the TE of Gümüshane, a province in the eastern region with poor land quality and lesser amounts of precipitation in general, increased from 32\% (Model 1) to 79\% when environmental effects with nonneutral specifications were incorporated (Model 4). In contrast, the TE of Istanbul located on the coastal region generally with favorable agro-climatic conditions, was estimated at $34 \%$ when no environmental effects were incorporated and it was down to $16 \%$ when environmental effects were assumed with nonneutral specification. The spread of TE scores is considerably increased with Model 4 (Figure 1d). Figures $2 \mathrm{a}$ and $2 \mathrm{~b}$ highlight changes in TE scores from Model 1 and Model 4 in the coastal and noncoastal regions. Furthermore, changes in TE scores are more pronounced in the coastal than noncoastal regions. One may also observe significant changes in the size and spread of TE scores when agro-climatic variables are incorporated in the production and TIE functions. One explanation may be that the agro-climatic conditions in the coastal provinces are more heterogeneous than those in the noncoastal provinces. For example, the standard deviation of land quality index is 0.24 for the coastal and 0.1 in the noncoastal regions.

The estimate of $\gamma$ parameter in all the models is fairly close to one, except in Model 4 where it is 0.763 (see Table A-1). ${ }^{9}$ While the estimate of $\gamma$ parameter for Models 2 and 4 are significantly different from one, those for Model 1 and 3 are not. 
Figure 1a Relative Frequency of TE Model 1

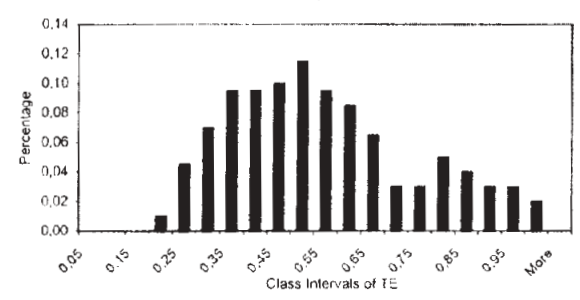

Figure 1c Relative Frequency of TE Model 3

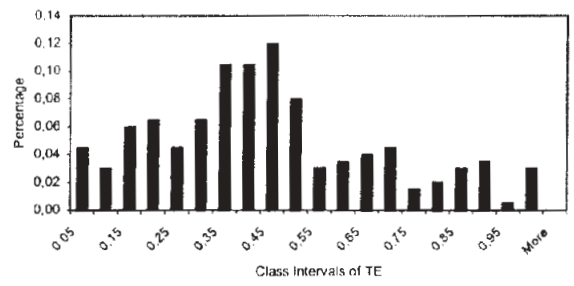

Figure 2a. Relative Frequencies of TE Coastal Regions (model 1, Model 4)

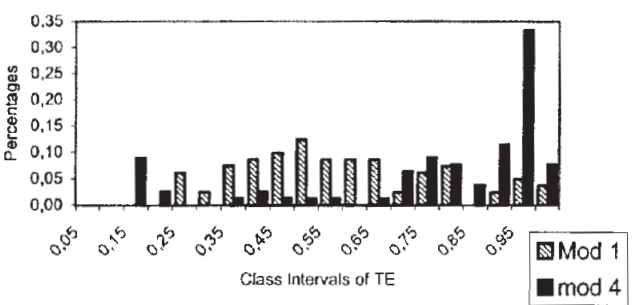

Figure 1b Refative Frequency of TE Model 2

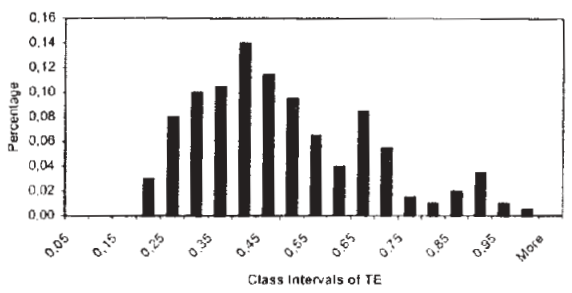

Figure 1d Relative Frequency of TE Model 4

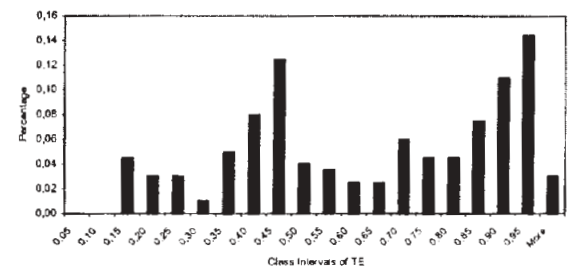

Figure 2b. Relative Frequencies of TE Non-coastal Regions (Model 1,Model 4)

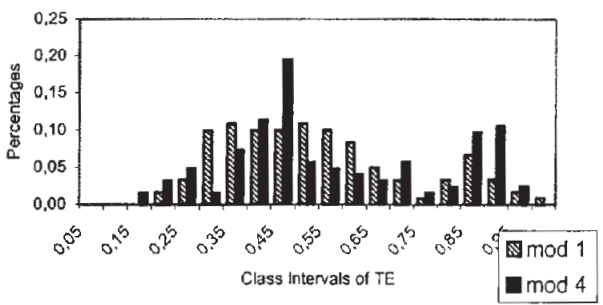

\section{CONCLUSION}

Technical efficiency studies of agriculture with regional data tend to ignore environmental effects on the assumption that such variables are random. We find that agricultural production is under the influence of variations of agro-climatic and other environmental variables that are location-specific. If these environmental variables are ignored, it may cause improper specification of the TIE in models of agricultural production. We illustrate the effect of agro-climatic factors under different model specifications using the Huang and Liu nonneutral stochastic frontier model with a TIE equation incorporating land quality, general crop pattern, land ownership distribution and precipitation, all as uncontrollable agro-climatic variables. In Model 4, the null hypotheses for various restrictions are all rejected.

Our results show that agro-climatic variables significantly affect directly and indirectly through interactions, mean output elasticities, economies to scale and technical efficiencies. 
The results have policy implications. The technical inefficiency implies that given the production technology, the provincial value-added can be increased without changing inputs. Also, if the effects of uncontrollable agro-climatic factors on TE are significant, but not accounted for, in a TIE equation, then interregional comparisons and recommendations for TE improvements may be incorrect. In such a case, it will make little or no sense to recommend corrective measures for productivity gains because the real source of technical inefficiency may be the uncontrollable agro-climatic effects.

\section{NOTES}

${ }^{1}$ See also Lee and Tyler (1978).

${ }^{2}$ Different distributions such as half-normal, exponential and gamma also are considered in different studies.

${ }^{3}$ For example, the null hypothesis of equal means of precipitation (in $\mathrm{mm}$ ) among seven regions of Turkish agriculture based on 62 year-observations for each region is strongly rejected (ANOVA, $F=493, F_{\text {crit. }}=2.2$ ).

${ }^{4}$ Sources on environment's direct effects and indirect effects through interactions on agricultural productivity include: Griliches (1960), Stallings (1960 and 1961), Tefertiller and Hildreth (1961), Coffing (1973), Demir (1976), Demir and Mahmud (1997 and 1998), Carter and Zhang (1998) and several reports by the CGIAR Centers - the Consultative Group on International Agricultural Research - IBRD.

${ }^{5}$ Regional dummies, standing for catch-all effects, are likely to obscure impacts from different sources and interactions.

${ }^{6}$ Due to the lack of data on capital services, number of tractors, modern orchards and crossbreed and hybrid animal population by provinces were incorporated in a single variable, capital, based on the principal component (PC) scores (Montgomery 1992, 353-60). The first PC explained $60 \%$ of the total variance; e.g., with an eigenvalue $=1.788$ out of 3 .

${ }^{7} \mathrm{~A}$ trend variable was tried both in the production function and in the technical inefficiency effects. It turned out to be statistically insignificant in both cases.

${ }^{8}$ Battese and Broca $(1997,405$ and note 9) and Ngwenya, Battese and Fleming $(1997,15)$ also experienced negative mean output elasticities with respect to labor.

${ }^{9}$ The FRONTIER V4.1 reports the estimated value of $\gamma$. The parameter, $\gamma=\left[\sigma^{2} / \sigma_{\mathrm{S}}{ }^{2}\right]$, where $\sigma_{\mathrm{S}}{ }^{2}=\sigma^{2}+\sigma_{\mathrm{v}}{ }^{2}, \sigma^{2}$ is the variance associated with the $U_{i t} \mathrm{~s}$ and $\sigma_{v}{ }^{2}$ is the variance of the error term $V$ in Eq. 1.

\section{ACKNOWLEDGMENT}

The contributions of our three anonymous Journal referees are gratefully acknowledged. We also like to thank Neil L. Arnwine at the Department of Economics of Bilkent University in Ankara for his comments.

\section{REFERENCES}

Afriat, S. 1972. Efficiency estimation of production functions. International Economic Review 33: 568-98.

Aigner, D. J. and S. F. Chu. 1968. On the estimating of the industry production function. American Economic Review 58: 826-39.

Aigner, D., C. A. K. Lovell and P. Schmidt. 1977. Formulation and estimation of stochastic frontier production function models. Journal of Econometrics 6: 21-37. 
Ali, M. and M. A. Chaudhry. 1990. Interregional Farm efficiency in Pakistan's Punjab: A frontier production function study. Journal of Agricultural Economics 41 (1): 62-74.

Battese, G. E. and T. J. Coelli. 1993. A stochastic frontier production function incorporating a model for technical inefficiency effects. Working Papers in Econometrics and Applied Statistics 69. Armidale, Australia: University of New England, Department of Econometrics.

Battese, G. E. and T. J. Coelli. 1995. A model for technical inefficiency effects in a stochastic frontier production function for panel data. Empirical Economics 20: 325-32.

Battese, G. E. and S. S. Broca. 1997. Functional forms of stochastic frontier production functions and models for technical inefficiency effects: A comparative study for wheat farmers in Pakistan. Journal of Productivity Analysis 8: 395-414.

Battese, G. E., S. J. Malik, and M. A. Gill. 1996. An investigation of technical inefficiencies of production of wheat farmers in four districts of Pakistan. Journal of Agricultural Economics 47 (1): 37-49. Brada, J. C. and A. E. King. 1994. Difference in the technical and allocative efficiency of private and socialized agricultural units in pre-transformation Poland. Economic Systems 18 (4): 363-76.

Carter, C. A. and B. Zhang. 1998. The weather factor and variability in China's grain supply. Journal of Comparative Economics 26: 529-43.

Coelli, T. 1996. A guide to FRONTIER version 4.1: Computer program for stochastic frontier production and cost function estimation. CEPA Working Paper 98/07. Armidale, Australia, 2351.

Coffing, A. 1973. Forecasting wheat production in Turkey. Foreign Agricultural Economic Report 85. Washington, DC: USDA.

Demir, N. 1976. The Adoption of New Bread Wheat Technology in Selected Regions of Turkey. Edited and abridged by CIMMYT. El-Batan, Mexico.

Demir, N. and S. F. Mahmud.1997. Problems, regional and technical efficiency differentials in the Turkish agriculture. Discussion Paper 98-12. Ankara, Turkey: Bilkent University, Department of Economics.

Demir, N. and S. F. Mahmud. 1998. Regional technical efficiency differentials in the Turkish agriculture: A note. Indian Economic Review 33 (2): 197-206.

DIE. State Institute of Statistics. 1994. General Agricultural Census: Results of the Agricultural Holdings (Household) Survey. Ankara, Turkey.

Griliches, Z. 1960. Estimates of the average U.S. supply functions. Journal of Farm Economics 42 (2): 282-93.

Huang, C. J. and J. T. Liu. 1994. Estimation of a nonneutral stochastic frontier production function. Journal of Productivity Analysis 5: 171-80.

Kalirajan, K. P., M. B. Obwona and S. Zhao. 1996. A decomposition of total factor productivity growth: the case of Chinese agricultural growth before and after reforms. American Journal of Agricultural Economics 78: 331-38.

KHGM. General Directorate of Village Affairs. Toprak ve Su Kaynakları Ulusal Bilgi MerkeziTürkiye Toprak Veri Tabanı (Database of Soil Classes), Ankara, Turkey.

Lee, L-F. and W. G. Tyler. 1978. The stochastic frontier production function and average efficiency. Journal of Econometrics 7: 385-89.

Meeusen, W. and J. van den Broeck. 1977. Efficiency estimation from Cobb-Douglas production functions with composed error. International Economic Review 18 (2): 435-44.

Montgomery, D. C. and E. A. Peck. 1992. Introduction to Linear Regression Analysis. New York: John Wiley.

Ngwenya, S. A., G. E. Battese and E. M. Fleming. 1997. The relationship between farm size and the technical inefficiency of production of wheat farmers in eastern Orange Free State, South Africa. Agrekon 36: 283-301.

Schmidt, P.1976. On the statistical estimation of parametric frontier production functions. Review of Economics and Statistics 58: 238-39.

Stallings, J. L. 1960. Weather indexes. Journal of Farm Economics 42: 180-86.

Stallings, J. L. 1961. A measure of the influence of weather on crop production. Journal of Farm Economics 45: 1153-62.

Tefertiller, K. R. and R. J. Hildreth. 1961. Importance of weather variability on management decisions. Journal of Farm Economics 45: 1163-69. 


\section{APPENDIX}

Table A-1. Maximum likelihood estimates of the translog stochastic production frontier without and with environmental variables, Turkish agriculture, 1993-95 a

\begin{tabular}{|c|c|c|c|c|}
\hline \multirow[b]{2}{*}{ Parameters } & \multirow[b]{2}{*}{$\begin{array}{c}\text { Without } \\
\text { environmental variables } \\
\text { Model } 1\end{array}$} & \multicolumn{3}{|c|}{ With environmental variables } \\
\hline & & $\begin{array}{l}\text { Neutral } \\
\text { Model } 2\end{array}$ & $\begin{array}{l}\text { Nonneutral } \\
\text { Model } 3\end{array}$ & $\begin{array}{l}\text { Nonneutral } \\
\text { Model } 4\end{array}$ \\
\hline Constant & $12.950(0.034)^{* *}$ & $13.100(0.096)^{* *}$ & $13.006(0.019) * *$ & $13.565(0.835)^{* *}$ \\
\hline$\beta_{A}$ & $0.208(0.043)^{* *}$ & $0.321(0.073)^{* *}$ & $-0.044(0.153)$ & $1.108(0.443)^{* *}$ \\
\hline$\beta_{L}$ & $0.533(0.094)^{* *}$ & $0.197(0.121)^{*}$ & $0.583(0.086)^{* *}$ & $1.812(0.819)^{*}$ \\
\hline$\beta_{K}$ & $0.712(0.102)^{* *}$ & $0.663(0.088)^{* *}$ & $0.856(0.101)^{* *}$ & $-0.748(0.548)$ \\
\hline$\beta_{A A}$ & $-0.246(0.064)^{* *}$ & $-0.108(0.068)^{*}$ & $0.927(0.130)^{* *}$ & $0.606(0.199)^{* *}$ \\
\hline$\beta_{L L}$ & $-0.073(0.160)$ & $-0.117(0.140)$ & $0.215(0.113)^{*}$ & $0.847(0.295)^{* *}$ \\
\hline$\beta_{K K}$ & $-0.166(0.082)^{*}$ & $-0.152(0.083)^{*}$ & $-0.018(0.056)$ & $0.569(0.249)^{*}$ \\
\hline$\beta_{A L}^{K K}$ & $0.132(0.139)$ & $0.008(0.139)$ & $-1.210(0.237)^{* *}$ & $-0.427(0.296)$ \\
\hline$\beta_{A K}$ & $0.593(0.140)^{* *}$ & $0.433(0.133)^{* *}$ & $0.004(0.133)$ & $-0.070(0.248)$ \\
\hline$\beta_{L K}$ & $0.080(0.208)$ & $-0.004(0.202)$ & $0.100(0.160)$ & $-1.634(0.567)^{* *}$ \\
\hline$\beta_{Q}^{L \Lambda}$ & & & & $-2.970(1.414)^{*}$ \\
\hline$\beta_{R}$ & & & & $0.218(0.582)$ \\
\hline$\beta_{Q Q}^{\kappa}$ & & & & $1.986(0.695)^{* *}$ \\
\hline$\beta_{A Q}$ & & & & $-0.915(0.444)^{*}$ \\
\hline$\beta_{A R}$ & & & & $0.867(0.371)^{* *}$ \\
\hline$\beta_{L Q}$ & & & & $-2.150(0.878)^{* *}$ \\
\hline$\beta_{L R}$ & & & & $0.056(0.304)$ \\
\hline$\beta_{K Q}^{L K}$ & & & & $2.534(0.703)^{* *}$ \\
\hline$\beta_{K R}$ & & & & $-1.187(0.281)^{* *}$ \\
\hline$\beta_{O R}$ & & & & $0.230(0.641)$ \\
\hline Constant & $0.667(0.085)^{* *}$ & $1.970(0.322)^{* *}$ & $2.176(0.301)^{* *}$ & $0.531(0.463)$ \\
\hline$\delta_{G}$ & - & $-0.779(0.525)$ & $-1.911(0.579)^{* *}$ & $-2.145(0.687)^{* *}$ \\
\hline$\delta_{O}^{G}$ & - & $-0.661(0.236)^{* *}$ & $-0.149(0.269)$ & $1.704(0.559)^{* *}$ \\
\hline$\delta_{C}^{Q}$ & - & $-0.515(0.102)^{* *}$ & $-0.641(0.185)^{* *}$ & $-1.156(0.392)^{* *}$ \\
\hline$\delta_{R}$ & - & $-0.269(0.088)^{* *}$ & $-0.619(0.118)^{* *}$ & $-0.277(0.259)$ \\
\hline$\delta_{A G}^{n}$ & - & - & $-1.881(0.653) * *$ & $-0.573(1.316)$ \\
\hline$\delta_{A Q}^{A U}$ & - & - & $1.455(0.463)^{* *}$ & $0.592(0.812)$ \\
\hline$\delta_{A C}^{A Q}$ & - & - & $-0.210(0.309)$ & $0.309 / 0.450)$ \\
\hline$\delta_{A R}$ & - & - & $-1.612(0.315) * *$ & $-0.080(0.582)$ \\
\hline$\delta_{L G}^{A n}$ & - & - & $-1.067(0.832)$ & $1.838(2.251)$ \\
\hline$\delta_{L Q}^{L U}$ & - & - & $0.910(0.549)^{*}$ & $-2.592(1.600)^{*}$ \\
\hline$\delta_{L C}$ & - & - & $-0.365(0.249)$ & $-0.845(0.781)$ \\
\hline$\delta_{L R}^{L L}$ & - & - & $1.622(0.353) * *$ & $2.500(0.448)^{* *}$ \\
\hline$\delta_{K G}^{L n}$ & - & - & $2.195(0.819)^{* *}$ & $-0.748(1.236)$ \\
\hline$\delta_{K Q}^{\mathrm{NU}}$ & - & - & $-1.315(0.508)^{*}$ & $2.608(1.117)^{* *}$ \\
\hline$\delta_{K C}^{\Lambda Q}$ & - & - & $0.513(0.277)^{*}$ & $1.133(0.538)^{*}$ \\
\hline$\delta_{K R}^{\Lambda C}$ & - & - & $-0.089(0.136)$ & $-2.502(0.617)^{* *}$ \\
\hline$\sigma_{S}^{2}$ & $0.196(0.027)^{* *}$ & $0.122(0.015)^{* *}$ & $0.107(0.010)^{* *}$ & $0.124(0.014)^{* *}$ \\
\hline
\end{tabular}


Table A-1. Continued from page 279

\begin{tabular}{|c|c|c|c|c|}
\hline \multirow[b]{2}{*}{ Parameters } & \multirow{2}{*}{$\begin{array}{c}\text { Without } \\
\text { environmental variables } \\
\text { Model } 1\end{array}$} & \multicolumn{3}{|c|}{ With environmental variables } \\
\hline & & $\begin{array}{c}\text { Neutral } \\
\text { Model } 2\end{array}$ & $\begin{array}{l}\text { Nonneutral } \\
\text { Model } 3\end{array}$ & $\begin{array}{l}\text { Nonneutral } \\
\text { Model } 4\end{array}$ \\
\hline $\begin{array}{l}\gamma \\
\text { Loglikelihood }\end{array}$ & $0.9999(5.2 \mathrm{E}-6)^{* *}$ & $0.951(5.2 \mathrm{E}-02)^{* *}$ & $0.999(8.7 \mathrm{E}-08)^{* *}$ & $0.763(0.136)^{* *}$ \\
\hline function & -87.1 & -61.8 & -41.7 & -30.7 \\
\hline
\end{tabular}

